\title{
The Overriding Role of Critical Thinking in Nahjolbalaqa 'Letters': Insights from Bloom's Cognitive Model
}

\author{
Parviz Alavinia \\ Urmia University, Iran \\ Shirin Malekzadeh \\ Department of English Language, Urmia Branch, Islamic Azad University, Urmia, Iran
}

\begin{abstract}
The dominion of Islamic world is replete with varied theological and spiritual masterpieces. One such outstanding work which has outlived its own time and the passage of time has not been able to undermine its beauty is Nahjolbalaqa (a road to eloquence). Nahjolbalaqa, the collection of Imam Ali's (peace be upon him) statements, consists of three different parts alternatively known as 'Sermons', 'Letters', and 'Wisdom'. The main purpose of this exploratory study is the textual analysis of 'letters' of Nahjolbalaqa according to Bloom's cognitive model. Based on Bloom's taxonomy, there are six different cognitive levels commencing with the most concrete and gradually moving toward the more abstract end of the continuum. These levels are termed Knowledge, Comprehension, Application, Analysis, Synthesis, and Evaluation. In the current scrutiny, all the 79 'letters' of Nahjolbalaqa, which amount to 255 titles if we consider their subcategories, have been analyzed according to Bloom's model in an attempt to come up with a vivid elucidation of their characteristics. As the final analysis of the gained upshots revealed, the majority of 'letters' pored over were found to comply with the levels of evaluation and knowledge in Bloom's model. Ultimately, it is hoped that the present study would prove helpful for commentators and all those who are in need of a deeper understanding of Nahjolbalaqa, particularly when it comes to finding out the corresponding level of abstraction for each individual 'letter'.
\end{abstract}

Index Terms—Bloom's Cognitive Taxonomy, abstraction, 'Letter' Analysis, cognitive level, Nahjolbalaqa

\section{INTRODUCTION}

Nahjolbalaqa, which is a collection of Imam Ali's invaluable guidelines and instructions for human beings, presented in the form of 'sermons', 'letters', and 'wisdom', is brimful of hints and signs that, by the unique style in which they have been expressed, fill the readers with profound levels of insight. In effect, the grandeur of Nahjolbalaqa emanates from the fact that its instructions apply to the entire humanity, are not intended for a particular group of people or for a specific epoch, and are consequently eternal. What Nahjolbalaqa, as one of the best and most credited samples of moral and spiritual instructions in the world of Islam, and for the entire humanity, describes is nothing but the portrait of a perfect human. Hence, an in-depth analysis of such a precious work will certainly help come up with a better understanding of the unique fluency and eloquence with which its priceless instructions have been expressed. As Karimi (2006) contends, eminent religious works have always been in the foreground of attention of great poets and writers, and so many illustrious figures, like Dostoyevsky, have been inspired by such marvelous masterpieces. Being drawn mainly by Quranic instructions, this Russian author, as Yahyapour (2006) avers, has talked of Allah and some Quranic characters like Mohammad and Jesus Christ in his works. Consequently, one won't be able to catch a full grasp of the paramountcy of analyzing Nahjolbalaqa, unless he/she realizes that this unrivaled tome encompasses a great collection of general and detailed issues from a variety of moral and educative arenas, and that its influence has been extended to the domain of Arab and Persian literature (Jafari, 2005).

In an attempt to further depict the real value of this splendid magnum opus, the researchers in the current probe strive to go about a partially full-fledged illumination of the linguistic and textual characteristics of Nahjolbalaqa. Actually, what the present study is mainly after is determining the appropriate level of Bloom's cognitive model to which each of the 255 titles and divisions of Nahjolbalaqa 'letters' belong. Bloom's model has been chosen in that it forms a sound basis for the classification of 'letters' into different classes according to their textual characteristics, where each category is said to possess a particular status in terms of conception and recognition. In line with Geertsen (2003), Bloom's model can be shown on a continuum, on which one extreme is to be taken as the highest level of abstraction, whereas the other has to do with highly concrete and tangible issues. It goes without saying that augmented levels of intellectual capabilities and cognitive growth are called for when approaching the abstraction side of the axis. Finally, in grappling with the focal postulations set forth in the present scrutiny, the following research questions were formulated by the researchers: 
- What level of abstraction can Nahjolbalaqa principles be said to enjoy?

- Can Nahjolbalaqa instructions be classified on the basis of cognitive characteristics?

- What levels of rationalism do Nahjolbalaqa instructions mostly entail?

- What issues are mostly accentuated by Nahjolbalaqa instructions?

\section{LITERATURE REVIEW}

In McKee's (2003) eyes textual analysis provides one with the opportunity to realize how the writer approaches the world around him. Furthermore, it is through a thorough-going analysis of the text that one can get to the unique meanings of different terminology and utterances utilized by the author. Accordingly, on account of the foregoing argumentation, a full grasp of different aesthetic aspects of Nahjolbalaqa won't be attainable via mere translational attempts and hence more profound evaluations are required to be able to understand its invaluable instructions. It is also worth noting that no studies, to date, have gone about the analysis of Nahjolbalaqa from a cognitive perspective. To come up with an ameliorated comprehension of the principles and delicate stylistic points raised in Nahjolbalaqa, commentators and other ordinary readers are in dire need of perusing the available scientific probes into varied facets of this masterpiece. Text-oriented investigations are of foremost salience in this respect, and the fact that a multitude of studies, thus far, have taken the form of textual analysis can be taken as further evidence in favor of the paramountcy of this branch of scientific probes (e.g. Soler, 2002; Flowerdew, 2003). The principal distinguishing feature shared by the body of research falling within the category of textual scrutiny is their attempt to pinpoint the true nature and specifications of the text under investigation.

Analyzing the textual features of a written piece of work has gained such a pivotal status that some scholars like Crookes (1986) contend that the explicit instruction of textual features of a written text might even prove fruitful in leading the students to produce and read such texts by themselves. Owing to the focal role textual analysis plays in elucidating the unique characteristics of the obtained data, the researchers in the current paper have made use of this productive method of scientific scrutiny. It has to be noted at this juncture that faced with the bulk of the content available, the researchers have tried to restrict the corpus to the 'letters' of Nahjolbalaqa only, to render the study more manageable. In so doing, the Action verbs occurring in the 'letters' have been classified on the basis of Bloom's model.

The thought-provoking content of Nahjolbalaqa has been scrutinized by several researchers, among whom mention can be made of Behnam (2003) who has analyzed some excerpts of Imam Ali's statements on the basis of two textoriented linguistic tenets, aimed at clarifying the veritable nature of Nahjolbalaqa principles, Mirqaderi (2006) who has evaluated the existing complaints in Nahjolbalaqa and appraised the discourse context and underlying inducement for each complaint, and Elahian and Pourrostami (2011) who have gone about the elaboration of human ineptitude in grasping the description of God given in Imam Ali's words.

An alternative group of researchers have strived to analyze Nahjolbalaqa instructions from philosophical and epistemological perspectives (e.g. Seyyedi, 2000; Jafari, 2000). Others have opted for a linguistic approach in their analysis of Nahjolbalaqa. Qonsouli (2000), for instance, has analyzed the occurrence of different speech acts in one of Nahjolbalaqa 'sermons'. Behnam (2003), on the other hand, has referred to the prevailing phonological, verbal, and structural orders in Nahjolbalaqa as an instance of attractions in Imam Ali's precious instructions. The implications of Nahjolbalaqa instructions for governance are among the other issues being attended to. Mousazade and Adli (2009), among others, have underscored the fundamental role of Nahjolbalaqa instructions in setting the criteria for the election of governmental leaders, having its origins in Islamic ideology. To wrap up this section, it must be stated that despite the preponderance of studies on different facets of Nahjolbalaqa, some of its linguistic features haven't been sufficiently scrutinized. As a case in point, the in-depth analysis of cognitive quality of Nahjolbalaqa instructions is among the issues that haven't yet been given due heed. Thus, the current study might be said to feature as an appropriate groundwork for future investigations driven by analogous orientations.

\section{Bloom's Cognitive Model}

Bloom et al. (1956) claim that their cognitive classification model equips the researchers with the proper means to pinpoint the existing similarities and differences among instructional programs and thereby arrange them in different cognitive levels. Bloom's model provides a nomenclature for the abstract and concrete set of activities going on in the mind. For instance, the amount of mental activity required for memorization is far less than the extent needed for, say, analyzing the data. Indeed, the logic behind adopting this model in the present investigation is its power in providing the researchers with a firm basis for placing each 'letter' of Nahjolbalaqa in a specific class, based on its unique characteristics, and thereby identifying the degree of cognitive intricacy for each individual 'letter'. Owing to the existence of similarities in the overall structure of some 'letters', such 'letters' can be grouped in their respective classes, based on their shared features.

Bloom's cognitive model incorporates six different levels, alternatively referred to as 'knowledge', 'comprehension', 'application', 'Analysis', 'Synthesis', and 'evaluation'. Each of these levels is characterized by a specific definition and hence consists of specific acts and features. As a matter of fact, Bloom has specified each single category through the use of some particular verbs, in an attempt to simplify the comparison among different mentality levels. Likewise, Nahjolbalaqa 'letters' can be categorized in different levels according to the unique nature they possess. For instance, if the main essence of a 'letter' is pertinent to the comparison of two things, it had better be placed in the category known 
as 'analysis', in that comparison is one of the distinguishing features for this category of Bloom's model (More explication regarding the categorization of 'letters' according to their overriding content is given in the ensuing section).

\section{Methodology}

\section{The Study Corpus and Procedure}

The utilized corpus in the current study consisted of the translated texts of 79 'letters' adopted from the 'letters' part of Nahjolbalaqa, which with their subdivisions amounted to a total of 255 'letters' (The translated version of Nahjolbalaqa used for the sake of the present scrutiny was the one done by Mohammad Mahdi Jafari). To perform the study, following Bloom's lead, all 'letters' were evaluated analytically and in sufficient detail by attending to each and every segment included in them, with the aim of revealing their cognitive characteristics. In other words, the reason behind such a detailed analysis of 'letters' was being able to assign them to one of the six levels in Bloom's taxonomy, i.e. the so-called categories of 'knowledge', 'comprehension', 'application', 'analysis', 'synthesis', and 'evaluation'.

The above-mentioned levels in Bloom's model are accompanied by particular delineations that facilitate the process of data analysis. The first level, known as 'knowledge', is characterized by the function of expressing specific information and specifying the incidents. 'Comprehension' is defined as the process of understanding the incoming information presented to an individual. 'Application' receives its major sense in the framework of applying rules, principles, conceptions, and theories in a novel context. What is meant by 'analysis' is the process of disintegrating the information into its basic components. 'Synthesis', on the other hand, has to do with the act of merging the existing theories in the form of a new or unique design. Finally, 'evaluation' pertains to the appraisal of the quality of the objects or beliefs according to specific tangible criteria (Shrum and Glisan, 1994).

Following the lead of Shrum and Glisan (1994), who regard each of these levels as bound with and characterized by some particular 'action verbs', the researchers are enabled to analyze and categorize Nahjolbalaqa 'letters' in one of the said cognitive classes, in terms of the verbs used in each of them. Some of the verbs relevant to each of the cognitive levels in Bloom's taxonomy are listed by Shrum and Glisan (ibid.) in the following manner:

1- Knowledge: to quote, to mention, to determine, to define, to name, to memorize, to repeat, and to discern.

2- Comprehension: to explain, to interpret, to change, to understand, to classify, to discuss, and to review.

3- Application: to act, to demonstrate, to illustrate, to apply, to practice, and to solve.

4- Analysis: to evaluate, to order, to divide, to compare, to distinguish, and to calculate.

5- Synthesis: to make, to produce, to believe, to modify, to collect, to manage, and to organize.

6- Evaluation: to justify, to support, to criticize, to choose, to evaluate, and to predict.

As is evident, different verbs in each category are indicative of their particular cognitive domain. The sixth level evaluation - is located in the abstraction extreme of the cognitive axis, and the first level - knowledge - signifies the most concrete point on the continuum. As a consequence, the features of different levels are not to be regarded as absolute; rather they are to be interpreted in terms of high or low degrees of abstraction or concreteness. For instance, 'comprehension' is considered as being more concrete than abstract. It is also worth noting that some words are liable to be related to a particular level indirectly; for example, a verb like 'care' can be indirectly associated with the verb 'define', and hence it can be classified under the category of 'knowledge'. As each letter was found to be established on the basis of a specific verb, it was essential that all the verbs be divided successive to evaluation and then classified in a specific category.

As stated earlier, an in-depth analysis of the content of 'letters' provided the researchers with a firm basis to demarcate the main verbs included in each 'letter'. Consequently, all 'letters' and their subdivisions were classified in 18 different groups. To come up with sound definitions for the verbs incorporated in each 'letter', use was made of a monolingual dictionary, for a bilingual dictionary was thought to be an improper source for grasping the exact definitions of words. Further justification for the application of monolingual dictionary in the current study comes from the fact that bilingual dictionaries mostly fall short of differentiating the words with close meanings but different nuances or shades of meaning. As a case in point, 'describe' and 'explain' tend to be considered synonymous in most bilingual dictionaries; nonetheless, in tandem with Oxford dictionary, there are minute differences between their English meanings. Thus, Hornby (2006) puts forth the following alternative definitions for the two words:

Describe: to say what sb/sth is like.

Explain: to tell sb about sth in a way that makes it easy to understand.

A more thoroughgoing account of the obtained upshots is given in the subsequent section.

\section{RESULTS}

In what follows a laconic exposition is provided of the initial results gained through the scrupulous analysis of the study corpus; Indeed all 'letters' have been classified on the basis of the occurrence of different groups of verbs in them. To submit a more reader-friendly account of the manner in which such groupings were materialized, the gained outcomes have been presented in the enumerated format:

1- To order: 45 'letters' out of the whole corpus of 255, were found to feature as the subdivisions of the verb order, in which the addressees were, in a way, ordered or exhorted to do something. Based on Bloom's taxonomy (see Shrum 
and Gilsen, 1994) all such instances of the verb 'order' were subsumed under the category of 'evaluation'. In keeping with this taxonomy, 'order' and 'exhort' are regarded as a part of the verb 'recommend'. Since verbs such as 'warn', 'exhort', 'guide', and 'order' belong to this cognitive level, all letters whose titles contain one of the relevant concepts like warning, precaution, exhortation, prevention, guidance, morality were categorized in this group. Examples of this include 'letter' titles like 'unhand the exaggeration', translation of the 21 st letter, 'exhort the human being by existence of the God', translation of letter 23 (2), 'order Meccan people not to get the wage', translation of letter 67 (4), 'real borders of this life', translation of letter 3 (2), and 'gathering the alms and justice culture', translation of letter 25.

2- To state: Altogether, 30 'letters' were grouped together as the subcategories of this verb, which has to do with 'vivid and clear expression' of a state or an action. This group falls under the category of 'knowledge', and is best epitomized via the verb 'state'. The letters entitled 'destiny of human in this world', translation of letter 31 (1), 'this world is a snake', translation of the 68th letter, 'the face of Koran', translation of the 77th letter, and 'O, you, the sight of Satan is the farm of disturbance', translation of letter 18 (1) count as the vivid examples of the cognitive level known as 'knowledge', since in all the said letters an attempt has been made to clarify the manner in which an action is (to be) performed.

3- To criticize: All in all, 21 'letters' out of the entire corpus were subsumed under this verb, which, in turn, belongs to the category of 'evaluation' in Bloom's model. Examples of the letters falling within this class are the ones entitled 'unsuitable work', translation of the 61st letter, 'the governor's duty toward people', translation of letter 50 (1), 'betrayal in safekeeping', translation of the 40th letter, and 'I made a mistake of you due to your father's honesty', translation of letter 71 (1).

'Undoubtedly, destroying others' responsibility and dealing with other's duties are a symbol of clear disability and invalid viewpoint' (translation of 61st letter)

4- To evaluate: 21 'letters', whose contents were relevant to the notions of appreciation and virtues were considered as the subdivisions of this verb, which, in turn, falls within the category of 'evaluation'. What is meant by 'evaluation' is the act of stating one's view regarding the quality, value, or degree of a topic or a person. This level can be characterized by words such as 'appreciation', 'worship', 'virtues', 'position', and 'feature'. Typical instances of this category include, 'appreciating Kuffa people', translation of the second letter, 'electing of proper colleague and counsel', translation of letter 53 (10), and 'we are created by our God', translation of the 28th letter.

'I hope God reward you, the citizens, via your prophet's clan' (translation of the second letter)

5- To uncover: 20 'letters' out of the whole corpus were categorized as the subdivisions of this verb, which has to do with revealing somebody's identity, and belongs to the level of 'analysis' in Bloom's taxonomy. Thus, all the concepts relevant to the term 'revealing', which is, by itself, a part of the verb 'uncover' were categorized in this class. Examples of this category include 'Othman progress report and viewpoints against it', translation of the first letter, 'leading astray', translation of the seventh letter, and 'uniqueness in Othman's believes and disagreement on his blood', translation of the 58th letter.

'I will aware you of Othman's activities, to hear it as you see him' (translation of the first letter)

6- To define: A total of 20 'letters' were grouped as the subcategories of this verb, which is regarded as a component of the level of 'knowledge'. Thus, letters that submitted a clear delineation of the nature or scope of issues were counted as falling within this category, examples of which being 'praying time', translation of the 52nd letter, 'to be on reasoning', translation of 14th letter, and 'attachment of materialists to the world', translation of letter 31 (20).

Say the initial praying when the sun shadow is at the size of a goat corral (translation of the 52nd letter)

7- To illustrate: 19 'letters' were grouped as the subdivisions of this verb, and were attributed to the level of 'application' in Bloom's taxonomy. The distinguishing feature shared by all these letters is the clarification of issues through the provision of examples. Examples of this category include 'God approbation in praying, and reasons of refusing them by God', translation of letter 31 (18), 'Imam describes himself in this world', translation of letter 45 (2), and 'precious suggestions for guarding the human values', translation of the 24th letter.

'O, you, a person whose generosity leads to the universe treasures let you to say praying, he has regarded your wrongdoings as one mistake, and your charities as ten right doings' (translation of letter 18 (31))

8- To describe: This verb was found to subsume 12 'letters' out of the whole corpus and was associated with the level of 'comprehension' in Bloom's model. The letters going about an elaboration of the details of an event were classified in this class, examples of which being, 'the best believer', translation of the 69th letter, and 'the abstinent people and their position in this world', translation of letter 27 (2).

' $\mathrm{O}$, know this fact that the best believer is a person who devotes his/her soul, clan, and wealth the most' (translation of the 69th letter)

9- To propose: 12 letters were regarded as the subcategories of this verb, which, in turn, falls within Bloom's 'synthesis' level. Epitomized by the verb 'propose', the letters in this group put forth an opinion or a plan that is being considered by the opposite side. The quintessential examples of this category are, 'Punishing the cruel', translation of letter 60 (2), and 'position of Imam Ali toward Bani Omiea, and inviting to allegiance', translation of the 75th letter.

'Receive the allegiance of your people, and come to me with a group of people' (translation of the 75th letter)

10- To demonstrate: A total of 11 'letters' out of the entire corpus were grouped as the components of this verb, which signifies the concept of proving or religious legalizing, and is, hence, a part of the 'application' class in Bloom's 
taxonomy. Some of the relevant example in this domain are 'counseling is only the right of immigrants and supporters', translation of the 60th letter, 'we are our creators' creatures', translation of letter 28 (9), 'complaining about his cousin', translation of letter 41 (1), and 'purchasing the right', translation of the 79th letter.

'Undoubtedly, governors were put to death before you, because they had prevented people from their rights' (translation of the 79th letter)

11- To respond: Altogether, 10 'letters' were found to be relevant to this category, which pertains to the act of responding to people and their claims, and is classified under the level of 'knowledge' in Bloom's model. As the typical examples of this category reference can be made to 'Imam's background in war against the polytheist, and his persistence', translation of letter 10 (3), 'the people wanted me, and I swore allegiance to them', translation of letter 54 (1), and 'we are our creator's creatures', translation of letter 28 (11 and 12).

'You have reminded me and my followers that you have nothing for us except for a sword. Indeed you made us laugh after the crying! Who has ever seen that Abdolmotaleb clan disengages the enemy?' (translation of letter 28 (11 and 12))

12- To support: 6 'letters' were associated with this category, which is indirectly related to the level of 'evaluation' in Bloom's taxonomy, and is typified via the verb 'support'. The best instance of this class is 'gathering the alms and tributes on the basis of justice', translation of the 25 th letter.

'And send someone who is compassionate, honest, and supportive to fetch the farm animals' (translation of letter 25 (4))

13- To practice: Falling within the level of 'application' in Bloom's model, this group was found to encompass a total of 6 'letters'. Letters entitled 'greediness of Imam Ali for solidarity unity among Muhammad followers', translation of letter 78 (2), and 'considering and going to the other world', translation of letter 31 (17), are the best epitomes of this category.

'O, you are going to face a difficult and arduous pass, the lighter on the pass, the easier' (translation of letter 31 (17))

14- To tell: Totally 5 'letters' were regarded as the subdivisions of this verb that is related to information transfer and instruction, and is subcategorized under the level of 'knowledge' in Bloom's classification. 'Instruction', 'value', and 'responsibility' best represent this cognitive level, and its archetypes among Nahjolbalaqa letters are 'war custom', translation of the 11th letter, and 'describing his own agent', translation of letter 46 (1).

'Thus your military camp should be in front of higher lands, mountainsides, or in the middle of winding rivers when you are fighting against the enemy or the enemy is fighting against you' (translation of the 11th letter)

15- To remember: Consisting of 5 'letters', this group is regarded as a subcategory of 'comprehension' level in Bloom's taxonomy, and gives an account of a situation or an instance from the past time. Typical instances of this category include 'real borders of the life', translation of letter 3 (2), and 'you are not an immigrant', translation of letter $64(3)$.

'A person, who has tried to accumulate his wealth, has spent his life on accumulation...' (translation of letter 3 (2))

16- To explain: Only 4 'letters' out of the entire corpus were classified as the subdivisions of this verb which is, by itself, related to the notion of explanation or straightforward expression of a topic. According to Bloom's model, this group is pertinent to the level of 'comprehension', and its finest example appears in the translation of letter 62 (4) from Nahjolbalaqa, which is entitled 'insistent viewpoint of Imam toward deviant people'.

'I swear to God that I will fight them, however I am alone and they are as big as the world, I am not afraid of loneliness' (translation of letter 62 (4))

17- To investigate: Simply 4 'letters' out the whole were found to be relevant to this group which is, in turn, a subcategory of the cognitive level of 'analysis' in Bloom's taxonomy. The best quotable example of this category is thought to be the translation of letter 67(1) from Nahjolbalaqa, titled 'Arrangement of pilgrimage to Mecca (Hajj) ceremony, and advising people'.

'Arrange the Hajj ceremony foe people, and remind them the God's days' (translation of letter 67 (1))

18- To classify: Finally, the remaining 4 'letters' out of the whole corpus of 255, were allotted to this group, which is classified under Bloom's 'analysis' level. 'Citizen Classes', translation of letter 53 (14), can be considered as one of the typical examples of this group.

' $O$, you pay attention to this point that citizens live in different classes, some of them do not become settled, unless by dependence on other classes' (translation of letter 53 (14))

As is evident from the data listed above, the letters implying 'order' are found to be the most important ones, as they outnumber the other categories. Now that the distribution of all Nahjolbalaqa 'letters' based on Bloom's model has been discussed in sufficient length, more careful and comprehensive groupings can be done by way of eliminating the redundancies from our categorization. Table 1 below represents the total frequency of 'letters' in each of the six major cognitive levels introduced in Bloom's model. 
TABLE 1

A SUMMARY OF ALL EXISTING VERBS IN DIFFERENT 'LETTERS', AND THEIR CORRESPONDING COGNITIVE LEVELS
\begin{tabular}{||l||l|l|}
\hline Cognitive level & Existing verbs in each level & Total number \\
\hline \hline Knowledge & To state, To define, To respond, To tell & 65 \\
\hline Comprehension & To explain, To describe, To remember & 21 \\
\hline Application & To demonstrate, To illustrate, To practice & 36 \\
\hline Analysis & To uncover, To investigate, To classify & 28 \\
\hline Synthesis & To propose & 12 \\
\hline Evaluation & To order, To evaluate, To criticize, To support & 93 \\
\hline
\end{tabular}

TABLE 2

THE RESULTS OF CHI-SQUARE FOR THE DISTRIBUTION OF LETTERS IN EACH COGNITIVE CATEGORY

\begin{tabular}{|c|c|c|c|c|c|}
\hline Cognitive level & Observed & Expected & $\overline{\text { df }}$ & Sig. & $\overline{2 \chi^{2}}$ \\
\hline Knowledge & 65 & 42.5 & 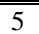 & 0.000 & 110.624 \\
\hline Comprehension & 21 & 42.5 & 5 & & \\
\hline Application & 36 & 42.5 & 5 & & \\
\hline Analysis & 28 & 42.5 & 5 & & \\
\hline Synthesis & 12 & 42.5 & 5 & & \\
\hline Evaluation & 93 & 42.5 & 5 & & \\
\hline total & 255 & - & - & & \\
\hline
\end{tabular}

\section{DISCUSSION}

Initial analysis of the data reveals that the outright majority of 'letters' fall within the cognitive level of 'evaluation' (judgment on the basis of specified and goal-oriented criteria) in Bloom's model $(\mathrm{N}=93)$. On account of this finding, it can be claimed that most of the words and sentences in Nahjolbalaqa feature as the quintessential instances of evaluating and ordering, categories in Bloom's model which demand very high levels of critical thinking. Evidence for this claim comes from Geertsen (2003), where he maintains that Bloom's model can be used as a tool to determine the high levels of abstraction, and then it follows that the higher the level of abstraction the higher the degree of critical thinking. Thus, the higher number of letters in 'evaluation' level is to be taken as proof for the importance of evaluation in Nahjolbalaqa. This further depicts the great value of Imam Ali's thoughts and statements, since as previously uttered most of the letters in this great masterpiece of his are germane to the notions of 'evaluation' and 'judgment', which are, by themselves, located at the highest level of abstraction. Next to evaluation, it is the 'knowledge' level that incorporates the most number of letters $(\mathrm{N}=65)$. Yet, as this level is situated in the concrete end of the cognitive axis, it can be deduced that two ultimate extremes of Bloom's continuum, i.e. knowledge and evaluation are characterized by possessing the highest number of letters. To justify this piece of finding, one might argue that evaluation without knowledge is impossible, and in case it is possible it proves to be destructive. On the other hand, to Imam Ali, who is called the leader of the faithful, mere knowledge is regarded as futile, unless it is utilized for the sake of some vital and crucial affairs such as 'judgment'. Furthermore, as Table 1 and its corresponding figure (shown below) help reveal, 'Synthesis' (which has to with the act of producing and combining topics and creating novel ones) is the level that encompasses the lowest number of letters. On account of the foregoing discussion, it can be said that Nahjolbalaqa puts forth a modern framework of art, mostly being materialized by way of its emphasis over some special features such as 'evaluation' and 'criticism'. The other notable feature of Nahjolbalaqa is the high level knowledge it draws on, which, in itself, is an indication of the omniscience of Imam Ali. As a case in point, military instruction requires expert knowledge of all aspects of military involvement and hence demands someone with comprehensive knowledge of its various perspectives. To sum it up, Nahjolbalaqa 'letters' are considered as explicit archetypes of profound knowledge and high levels of critical thinking (The cognitive quality of all Nahjolbalaqa 'letters' is illustrated in Figure 1).

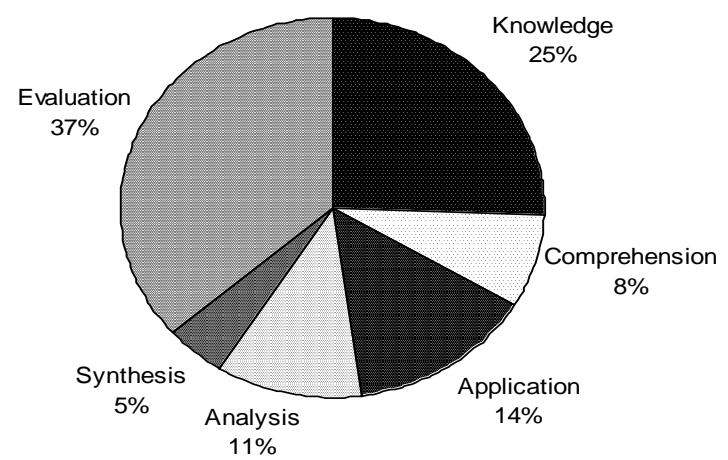

Figure 1Cognitive quality of Nahjolbalaqa letters on the basis of Bloom model 


\section{CONCLUSION}

The researchers in the current study were after coming up with a proper outlook regarding the cognitive status of Nahjolbalaqa 'letters' in terms of Bloom's taxonomy. As the findings summarized in Table 1 and Figure 1 illustrated, the majority of the 'letter' titles in Nahjolbalaqa were found to fall within the category of 'evaluation'. Indeed, 'evaluation' and measurement have long been regarded as the most important concerns of mankind throughout the history (Farhady, et al. 2008). The classification of 'letters' based on Bloom's model provides us with a better means to grasp the focal concepts raised in each 'letter'. Thus, the findings of the present investigation might help the analysts and instructors, dealing with Nahjolbalaqa for different purposes, raise people's consciousness of this great masterpiece of Imam Ali's. As the issues become broader and more professional, general concepts, at times, need to be analyzed in detail to be able to clarify the specialized and intricate conceptions, as is the case with a teacher or a researcher who may draw simply on certain pieces of information extracted from a particular book. Analysts contending with notions such as 'judgment' and 'criticism' in their discussions, are liable to make use of the sample 'letters' subsumed under 'evaluation' class, in order to substantiate their claims via tangible examples. Nonetheless, it should be noted, at this juncture, that an attempt to translate some certain verbs in Persian might provide us with seemingly synonymous cases, which are likely to increase the viability of committing errors in scientific scrutiny. To cope with this potential problem, then, Oxford monolingual dictionary has been utilized in the current study to be able to clarify the delicate differences among the verbs mentioned in Bloom's cognitive model, and to classify the 'letters' in proper classes by sticking to the precise intended connotations of the verbs. In sum, the major conclusions gained in the present study have been listed below:

- Most of the 'letter' titles in Nahjolbalaqa belong to the cognitive level of 'evaluation' in Bloom's model. As 'Evaluation' is located in the most abstract end of Bloom's continuum - the highest cognitive level - it can be deduced that Imam Ali's instructions are characterized by a high level of cognition.

- Bloom's model is composed of a variety of different verbs that make it apt as a basis for classifying the texts on the basis of different characteristics. The obtained findings in the current study indicate that 'evaluation' and 'judgment' are the most important elements of Imam Ali's statements.

- Next to 'evaluation' level, it is 'knowledge' that features as the second prevalent category of Bloom's model apropos the studied corpus of 'letters'. This exalted position of 'knowledge' in Imam Ali's 'letters' can be taken as further evidence for his high level of intellectuality. An alternative interpretation of this piece of finding might be that without 'knowledge', which can be regarded as the prerequisite for 'evaluation', the true value of Imam Ali's judgment is likely to remain disentangled.

To put it in a nutshell, the Classification of Nahjolbalaqa instructions is thought to play a crucial role in the meaningful teaching of this invaluable masterpiece of Imam Ali's. As a direct consequence of such a clear-cut categorization, instructors and all those who are somehow involved with pedagogical issues are enabled to put forth vivid delineations of different concepts in Nahjolbalaqa, and teach these valuable concepts in accordance with the students' level of cognitive growth. It has to be recapitulated, at this point, that the majority of 'letters' in Nahjolbalaqa are characterized by the highest level of 'abstraction', which, in itself, implies the optimum level of critical thinking possessed by its author, i.e. Imam Ali. Yet, to come up with a more comprehensive classification, further studies grappling with a full-fledged investigation of Imam Ali's 'sermons' and 'wisdom' are also called for. After all, it must be reiterated that Nahjolbalaqa is a genuine masterpiece, which takes account of not only the religious perspectives, but varied branches of science, such as epistemology, philosophy, anthropology, botany, and many other scientific domains, and each single page from this glorious tome leads the reader through a long journey, in which s(he) is endowed with a thorough-going conceptualization of real human being and the entire universe of which $\mathrm{s}(\mathrm{he})$ is a tiny part.

\section{REFERENCES}

[1] Behnam, B. (2003). The literary position of Nahj al-Balaga: A linguistic analysis of a selection of Imam Ali's language (pbuh). Maqalat Wa Barrasiha, 35(72), 61-79.

[2] Bloom, B. S. Engelhart, M. D. Furst, E. J. Hill, W. H. \& Krathwohl, D. R. (1956). Taxonomy of educational objectives Handbook 1: The cognitive domain, New York, David Mackey.

[3] Crookes, G. (1986). Towards a validated analysis of scientific text structure, Applied Linguistics, 7(1), 57-70.

[4] Elahian, M., \& Poorrostami, H. (2011). Theological outputs of the traditions designating the interrelation between Quran and the lineage. Andishe-e-Novin-e-Dini, 6(23), 113-132.

[5] Farhady, H. Ja'farpur, A. \& Birjandi, B. (2009). Testing language skills: From theory to practice, SAMT Publication, Iran: Tehran.

[6] Flowerdew, J. (2003). Signalling nouns in discourse, English for Specific Purposes, 22(4), 329-346.

[7] Geertsen, H. R. (2003). Rethinking thinking about higher-level thinking, Teaching Sociology, 31(1), 1-19.

[8] Ghonsuli, B. (2000). A discourse analysis of the $112^{\text {th }}$ Khutba in Nahj-ul-Balaghehe. Journal of Language and Literature Faculty of Letters and Humanities of Mashhad, 33(3-4), 571-580.

[9] Hornby, A. S. (2006). Oxford advanced learner's dictionary of current English. Oxford University Press.

[10] Jafari, M. (2000). Nahjolbalaqa: Exhilarating rhythm. Teb va Tazkieh, 38, 86-90.

[11] Jafari, S. M. M. (2005). The influence of Nahjul Balagha on Persian literature. Journal of Social Sciences and Humanities of Shiraz University, 22(1 (42)), 1-18. 
[12] Karimy, J. (2006). An investigation on the role and effect of Koranic verses and orientalism in the formation of Pushkin's poetry: "Qoranic allusion poem". Pazhuhesh-e Zabanha-ye Khareji, 30, 95-108.

[13] McKee, A. (2003). Textual analysis: A beginner's guide. SAGE Publication.

[14] Mirghaderi, S. F. A. (2006). Complaints of Imam Ali (Phuh) In Nahjolbalagha. Journal of Social Sciences and Humanities of Shiraz University, 25(3 (48)):199-213.

[15] Mousazadeh, Z., \& Adli, M. (2009). The criteria for selecting and appointing managers based on the assumption of merit as stated by Nahjolbalagheh. Strategic Management Thought, 3(1 (5)):103-132.

[16] Seyyedi, H. (2000). Imam Ali's Discourse in Nahj-ul-Balagheh. Journal of Language and Literature Faculty of Letters and Humanities of Mashhad, 33(3-4), 629-642.

[17] Seyyed Razi, A. M. H. (359-406 A.H. Circa A.D. 938-985), Nahjolbalaqa', translated by Mohammad Mahdi Jafari (1 ${ }^{\text {st }}$ edition). Tehran, Zekr Publication.

[18] Shrum, J. L., \& Glisan, E. (1994). Teacher's handbook: Contextualized language instruction. Boston, MA, Heinle \& Heinle.

[19] Soler, V. (2002). Analyzing adjectives in scientific discourse: An exploratory study with implications for Spanish speakers at advanced university level, English for Specific Purposes, 21(2), 369-394.

[20] Yayhapour, M. (2006). Study of the Islamic concepts in some of Theodore Dostoyevsky's works and the reasons for his interest in these concepts. Pazhuhesh-e Zabanha-ye Khareji, 30, 145-159.

Parviz Alavinia was born in Urmia, 1978. He got his PhD in TEFL/TESOL from Allameh Tabataba'i University in Tehran, Iran, 2010, his MA (in the same major) from The University for Teacher Training in Tehran, Iran, 2004, and his BA degree from Urmia University, Urmia, Iran, 2001.

$\mathrm{He}$ is currently involved as a full-time assistant professor and staff member at Urmia University. Two of his recent publications are listed below: Alavinia, P. (2011a). Emotional Engineering through the Application of Fuzzy Logic: Enhancing Emotional Intelligence by Raising Awareness of Emotions. Germany: VDM Verlag. Alavinia, P. (2011b). Toward the Refutation of Herrnstein and Murray's Maxims: Is (Emotoinal) Intelligence Acquirable and Modifiable through Scooling? Germany: Lambert Academic Publishing. His main areas of interests include psycholinguistics, philosophy of language, critical discourse analysis and particularly emotional intelligence.

He used to be TELLSI member from 2004 to 2008, and a member of the Linguistic Society of Iran from 2003 till 2006, and has been L-test member since 2003.

Shirin Malekzadeh is currently an MA student in TEFL at Urmia Islamic Azad University (Science and Research Branch). She got her BA in TEFL from Islamic Azad University of Mashhad, Iran, 2010.

She is mainly interested in cultural, social, and psychological studies regarding foreign language learning and teaching. 